\title{
DINÂMICAS PRODUTIVAS DA ECONOMIA DE EXPORTAÇÃO NO MATO GROSSO DO SUL - BRASIL
}

\author{
The Productive Dinamics of the Exportation Economy in the State of Mato Grosso do Sul - Brazil
}

\author{
Lisandra Pereira Lamoso*
}

\begin{abstract}
Resumo
As dinâmicas produtivas da economia de exportação são a face interna da economia internacional. Os fluxos de comércio materializam as demandas do comércio internacional no território. As dinâmicas produtivas envolvidas pela economia de exportação no Mato Grosso do Sul são formadas pela rede produtora de commodities do complexo soja, minério de ferro, pelas exportações de carne bovina e subprodutos da pecuária, pela produção da agroindústria de aves e suínos e, mais recentemente, a produção de celulose e etanol. As estruturas produtivas estão apoiadas em vantagens comparativas e pelas vantagens competitivas que se formaram durante o processo de ocupação e povoamento, principalmente na porção sul do estado. Essa dinâmica produtiva tende a se acentuar com os incentivos dados pelo Estado para a internacionalização das empresas de capital privado e pelas metas da política industrial vigente. Este texto discute a relação entre o comércio exterior e as dinâmicas produtivas no Mato Grosso do Sul.
\end{abstract}

Palavras-Chave: Comércio exterior, exportações, internacionalização de empresas, commodities, agronegócios

\begin{abstract}
The productive dynamics of the exportation economy are the internal profile of the international economy. Trade flow materializes the foreig trade demands on the Territory. The productive dynamics involved by the exportation economy in the state of Mato Grosso do Sul are formed by the commodities' productive chain of the complex soya-beans, iron-minery, by the exportation of beef and cattle-production sub products, by the production of celluloses and ethanol. The productive structures are supported by comparative advantages and by the competitive advantages that are formed during the occupation and community-formation process, especially in the south part of the state. This dynamic tends to be accentuated by the incentive given both by the State in order to internationalize private-capital companies and by the goals for the current industrial policy. This text discusses the relation between external commerce and the productive dynamics in Mato Grosso do Sul.
\end{abstract}

Key words: Foreign trade, exportations, internationalization of the companies, commodities, agribusiness.

\section{Resumen}

Las dinámicas productivas de la economía de exportación son las manifestaciones internas de la economía internacional. Los flujos comerciales materializan las exigencias del comercio internacional en el territorio. La dinámica productiva de la economía de exportación que participa en Mato Grosso do Sul se forma por el productor de la red de productos de soja, carne vacuna, mineral de hierro y productos avícolas. Esta producción está apoyada por el impulso dado por el Estado para la internacionalización de las empresas de capital privado y por los objetivos de la política industrial. Este texto analiza el comercio exterior como parte de la política industrial del segundo Gobierno de Lula y el impacto de la política sobre el uso de las ventajas comparativas para la obtención de un superávit comercial en Mato Grosso do Sul.

Palabras clave: Comércio exterior, exportación, internacionalización de las empresas, commodities.

(*) Pesquisadora do CNPq, Prof ${ }^{\mathrm{a}}$. Drª do Programa de Pós-graduação em Geografia da Universidade Federal da Grande Dourados, Caixa Postal 322 - Rodovia Dourados-Itahum, km 12 - CEP 79.825-070, Dourados (MS), Brasil, Tel (+ 55 67) 3410 2270 - lisandralamoso@ufgd.edu.br 


\section{INTRODUÇÃO}

A economia de exportação é um vetor que acentua as influências do mercado internacional no território e nesse sentido trata-se um recorte para a compreensão das dinâmicas produtivas regionais. O objetivo deste texto é discutir a inserção do Mato Grosso do Sul na economia internacional e como os vetores externos formam territorialidades econômicas definidas pelo poder hegemônico das principais corporações transnacionais. Esta contribuição particular pretende colaborar com aquelas que pesquisam as relações de trabalho e poder no campo, as transformações no urbano e a ordem imaterial que "privatiza" o território, na expressão de Santos (1994).

Nosso maior desafio (e dificuldade) tem sido aproveitar o conhecimento produzido pela Economia para compreender as dinâmicas produtivas territoriais, sem nos perdermos no emaranhado de índices, quantidades e volumes que caracterizam a economia exportadora. Alguns procedimentos metodológicos têm sido utilizados nessa tentativa. Primeiro, consideramos fundamental a articulação multiescalar entre o regional (entendido como o sub-espaço de Mato Grosso do Sul, enquanto unidade da federação), o nacional (território brasileiro) e o global (a economia internacional representada, nesta discussão, pelos principais mercados mundiais e os principais parceiros comerciais do estado). Essa articulação multiescalar foi inspirada em Rangel (1999), que elaborou uma proposta que relaciona lado externo/interno e pólos interno/externo para construir sua leitura sobre a formação econômica e social brasileira.

A manifestação dos vetores internos e externos é possibilitada por um conjunto de normas. Sobre essas, Santos (1996) já havia chamado a atenção sobre seu poder explicativo e ordenador. No conjunto das normas, reunimos as induções que foram definidas pela atual política industrial brasileira, a Política de Desenvolvimento Produtivo (PDP), do segundo mandato do Governo Lula (2007-2010), por considerar que esta afeta sobremaneira a economia e o território de Mato Grosso do Sul.

O desenvolvimento econômico brasileiro tem, historicamente, recebido influências do centro dinâmico do capitalismo e sua economia exportadora está organizada em função do mercado externo. Primeiro, sob a influência do capitalismo mercantil português, depois o capitalismo industrial da Inglaterra e, posteriormente, o capital financeiro dos Estados Unidos.

A cada período, o território mato-grossense (a partir de 1979, sul-matogrossense), se organizava para atender aos impulsos externos, sob o comando da "região concentrada", com destaque para a economia paulista. A região Sudeste, em particular o estado de São Paulo, exerceu o poder de espraiar as demandas do mercado interno, definindo, na divisão territorial do trabalho, o Mato Grosso do Sul como uma extensão da economia do Sudeste - uma afirmação clássica registrada por Goldenstein e Seabra (1989). A partir da incorporação do Cerrado pelo cultivo de soja, para reduzir o impacto causado pelo Choque do Petróleo, o Mato Grosso do Sul saiu do binômio trigo/ gado para soja/gado e foi gradativamente ligado ao comércio internacional através das exportações de produtos do complexo soja e carne bovina.

Segundo Rangel, "a economia brasileira, desde a descoberta, desenvolve-se como complemento de outras economias - dos países que, sucessivamente ocupam a vanguarda no desenvolvimento da humanidade" (RANGEL, 2005, p. 322). A prioridade dada ao comércio exterior foi histórica, mas pela força da inércia e da nossa formação socioespacial, ela tem sido presente desde então, pois participamos do conjunto dos países ocidentais nos quais o capitalismo se desenvolve com base na dependência do mercado externo. Diferente da opção chinesa, que pautou o desenvolvimento econômico em seu próprio mercado interno, inicialmente.

O comércio exterior é a via mais visível da relação entre a economia brasileira e os demais países. As estruturas técnicas e produtivas envolvidas na atividade exportadora materializam no espaço regional a face da relação externa da economia nacional.

Neste texto, além dessa introdução, organizamos a discussão em três itens. O primeiro, "Características do Desenvolvimento Econômico Recente e a Retomada da Política Industrial", sintetiza, 
para o interesse desse texto, alguns fatos da política econômica a partir dos anos oitenta. O segundo aborda "O Comércio Exterior Brasileiro e as Exportações de Mato Grosso do Sul”. Neste comentamos algumas características da Política Industrial, Tecnológica e de Comércio Exterior (PITCE) e da Política de Desenvolvimento Produtivo (PDP), ambas elaboradas pelo Governo Lula, a primeira vigente durante o primeiro mandato (2003-2006) e a PDP durante o segundo (2007-2010). O terceiro item deste texto enfoca “As Relações Entre a Economia Exportadora e o Território". Neste apresentamos um balanço do comportamento das exportações brasileiras, quais produtos dominam a pauta do estado do Mato Grosso do Sul e quais são os principais agente exportadores. No quarto item, os três primeiros são utilizados na argumentação que norteia este texto, baseada na hipótese de que as normas vigentes fortalecem uma estrutura produtiva agroprimária-mineral, dificultando o processo de verticalização, provocando permanências de uma ordem conservadora política que transforma o território em refém dos vetores externos, limitando as possibilidades de horizontalizar os benefícios do crescimento econômico.

\section{CARACTERÍSTICAS DO DESENVOLVIMENTO ECONÔMICO RECENTE E A RETOMADA DA POLÍTICA INDUSTRIAL}

Nos anos oitenta, a coincidência da fase depressiva no Ciclo Longo (que afetou o centro dinâmico do capitalismo) com a fase depressiva no Ciclo Médio de Juglar (juglarianos brasileiros) representou um período de depressão apelidado, eufemisticamente de "década perdida" por alguns economistas. A segunda metade dos anos oitenta (1985-1990), ocorreu sob a presidência de José Sarney (ex-presidente da Aliança Renovadora Nacional, a ARENA, partido da Ditadura). A década terminou com dois acontecimentos relevantes: a vitória de Fernando Collor de Melo, ainda viva na lembrança nacional; e o encontro promovido pelo Institute for International Economics (IIE), de onde saiu um conjunto de políticas conservadoras que norteou o acesso ao crédito pelos países subdesenvolvidos. Estas orientações ficaram conhecidas como "Consenso de Washington". Em síntese, as recomendações foram: 1) Limitação dos gastos do Estado à arrecadação; 2) Redução dos gastos públicos; 3) Reforma tributária; 4) Liberalização e desregulação financeira com redução da participação do Estado; 5) Manutenção de taxa competitiva de câmbio; 6) Liberalização do comércio exterior; 7) Eliminação das restrições ao capital externo; 8) Privatizações; 9) Flexibilização das leis trabalhistas e 10) Defesa da propriedade intelectual.

Na pauta política, Collor havia imposto o que Sader (2010, p.23) chamou de "primeira versão do projeto neoliberal no Brasil", valorizando o tema da crise fiscal do Estado e da luta contra a inflação. Mesmo o impeachment, em 1992, não conseguiu barrar a hegemonia do pensamento neoliberal que ganhava força em todo continente latino-americano, com dois "garotos-propaganda" de destaque: México (que enfrentou uma importante crise em 1994) e a Argentina, em 2002.

Na seqüência do Governo Collor, foi vitoriosa a proposta conservadora que utilizou o discurso da luta contra a inflação como um escudo que mascarava a imposição de interesses de frações de classe. Na seqüência, a estabilização representada pelo Plano Real garantiu a vitória do Ministro da Economia de Itamar Franco, Fernando Henrique Cardoso. Segundo Sader (2010, p.25) "A queda de Collor interrompeu a primeira tentativa de imposição do modelo neoliberal. No entanto, o novo consenso estava instalado, criminalizando o Estado e suas formas de regulação". A discussão de políticas alternativas para a retomada do crescimento econômico foi excluída da pauta.

Os dois Governos de Fernando Henrique Cardoso fortaleceram a subordinação nacional à hegemonia norte-americana, enfraqueceram as relações com o Mercosul e quase colocaram a economia brasileira a serviço da ALCA. O Consenso de Washington foi fielmente aplicado, com particular destaque para a política de privatizações e para a liberalização do comércio exterior.

Em 2002, por conquista das forças mais progressistas e pelo desgaste do modelo neoliberal, assumiu a República, na terceira tentativa eleitoral, o Partido dos Trabalhadores. No primeiro mandato houve semelhanças em termos de medidas macroeconômicas com o governo anterior. A 
presidência do Banco Central com Henrique Meirelles e a independência da política monetária, mesmo quando se discutia a necessidade de um projeto de caráter neodesenvolvimentista, foi sintomática do conservadorismo que fez o governo perder vários aliados ideológicos.

Em termos de política industrial, o Governo optou por mantê-la abrangente, lançando em 2004 a Política Industrial, Tecnológica e de Comércio Exterior (PITCE) e em 2008 a Política de Desenvolvimento Produtivo (PDP).

Política industrial pode ser definida como um conjunto de normas que tem por objetivo induzir ou incentivar determinados padrões de desenvolvimento industrial. São, por isso, provocadoras de sistemas territoriais de produção que podem ter quatro tipos de desdobramentos: 1) ausência de integração e de territorialização da atividade econômica e da ação da empresa; 2) presença de integração e ausência de territorialização; 3) presença de territorialização com integração e 4) ausência de territorialização com integração. Esta tipologia dos sistemas territoriais de produção baseado no grau de integração do sistema produtivo com o território foi extraída de Maillat (2002, p.11).

Almeida (2009) elaborou um quadro síntese que apresenta os quatro tipos de política industrial utilizados na América Latina. O quadro apresenta políticas de cunho setorial, políticas voltadas ao estímulo à inovação (também conhecidas como neo-shumpeterianas), políticas criadas para aperfeiçoar os marcos regulatórios e aquelas que são destinadas à promoção de Arranjos Produtivos Locais (APL), sendo estes os que, a priori, comportam maior grau de territorialização e integração.

Tabela 1 - Tipos de Política "Industrial" na América Latina

\begin{tabular}{l|l|l}
\hline \multicolumn{1}{c|}{ TIPO DE POLITICA } & \multicolumn{1}{c}{ Objetivo } & \multicolumn{1}{c}{ Exemplos } \\
\hline Política de promoção setorial. & $\begin{array}{l}\text { Aumentar a competitividade de setores já } \\
\text { existentes e criar novos elos na cadeia de } \\
\text { produção. }\end{array}$ & $\begin{array}{l}\text { Indústria automobilística, têxtil e } \\
\text { vestuário, etc. }\end{array}$ \\
\hline $\begin{array}{l}\text { Políticas de fomento à inovação e } \\
\text { construção de setores dinâmicos (neo- } \\
\text { schumpeteriano). }\end{array}$ & $\begin{array}{l}\text { Fomentar a inovação e a criação de setores } \\
\text { em atividades intensivas em tecnologia e/ou } \\
\text { conhecimento. }\end{array}$ & $\begin{array}{l}\text { Fármacos, biotecnologia, software, } \\
\text { nanotecnologia }\end{array}$ \\
\hline $\begin{array}{l}\text { Políticas de regulação. } \\
\text { Políticas de Promoção de APLs. }\end{array}$ & $\begin{array}{l}\text { Promover a modernização e competitividade das } \\
\text { pequenas e médias empresas nos clusters. }\end{array}$ & $\begin{array}{l}\text { Aglomerações produtivas nos de energia, } \\
\text { setores de calçados, móveis e } \\
\text { confeccãa. }\end{array}$ \\
\hline
\end{tabular}

Extraído de Almeida (2009).

A PITCE foi elaborada no contexto de sucessivas crises internacionais que chamaram a atenção da América Latina depois da derrocada do México e da Argentina. Os diagnósticos elaborados apontaram a necessidade de buscar o maior crescimento econômico em três frentes: a) promover o desenvolvimento tecnológico e a inovação, b) melhorar a eficiência do sistema produtivo e c) expandir as exportações.

A incorporação do comércio exterior na pauta da política industrial ocorreu porque o Governo considerou que a retomada do desenvolvimento econômico necessitava do que Coutinho (2003) chamou de "sustentabilidade macroeconômica" e para mantê-la o poder público avaliou que era condição sine qua non a obtenção de um elevado superávit comercial. Este teria como objetivo "reduzir a vulnerabilidade do balanço de pagamentos, recuperar um volume expressivo das reservas próprias de divisas e viabilizar uma queda segura e irreversível da taxa de juros" (COUTINHO, 2003, p.334).

No segundo mandato, os diagnósticos consideraram que o país apresentava uma estrutura produtiva diversificada e com consideráveis vantagens comparativas na produção de produtos agropecuários, minerais e siderúrgicos. Tanto o diagnóstico quanto a implementação, de fato legitimaram a dependência que os superávits mantêm com relação ao agronegócio e às exportações de minério de ferro (estes representam quase 10\% do total da balança comercial). $\mathrm{O}$ sub-espaço do 
Mato Grosso do Sul, além de possuir redes materiais e objetos técnicos (rede de armazenagem, de transporte) e produzir commodities, participa da política econômica nacional com a riqueza de sua rede de relações sociais e políticas e a expertise técno-comercial, acumulada pelos principais agentes exportadores. A expansão do setor agro-primário-exportador alcança o sul do Piauí, Balsas (Maranhão) e Luis Eduardo Magalhães (na Bahia), que também fazem parte do processo. Novas siglas são inventadas da toponímia das regiões produtoras, como MAPITO (Maranhão, Piauí e Tocantins).

APDP traçou metas para uma retomada do planejamento com visão de longo prazo, o que é um aspecto positivo. As quatro macrometas ou metas-país estabelecidas para 2010 foram: a) Aumento da taxa de investimento, ou seja, da formação bruta de capital fixo; b) Ampliação das exportações brasileiras no comércio mundial; c) Elevação do investimento em Pesquisa \& Desenvolvimento e d) Ampliação do número de Pequenas e Médias empresas exportadoras. (MDIC, 2010). Além disso, o Governo Federal tem implementado uma política de incentivo ao processo de internacionalização de empresas privadas de capital nacional, através de recursos do BNDES.

Na elaboração da Política de Desenvolvimento Produtivo, novamente o comércio exterior foi pautado como necessidade e como estratégia, pois segundo Presidente do BNDES, "a arte da política industrial e de comércio exterior reside precisamente em combinar a captura de novas oportunidades sem abandonar as bases da competitividade já adquiridas nas commodities intensivas em recursos naturais, escala, energia e trabalho (COUTINHO, 2003, p.339).

No Mato Grosso do Sul, uma das vantagens competitivas está dada pela pecuária, através das exportações de carne bovina congelada ou refrigerada, e o fortalecimento das empresas que participam do ramo de proteína animal. Para execução da política de fortalecimento dos grupos privados nacionais, o BNDES tem se utilizado da BNDESPar, uma holding que controla as empresas nas quais o Banco detém ações.

A BNDESPar obteve, entre 2007 e 2009, participações acionárias no Grupo Bertin, JBS, Marfrig e Perdigão/BR Foods. A BR Foods surgiu da fusão entre a Sadia e Perdigão.

Tabela 2 - Principais Investimentos da BNDESPar no Setor de Proteína animal

\begin{tabular}{l|c|c}
\multicolumn{1}{c|}{ EMPRESA } & Participação Acionária (\%) & Ano dos Investimentos \\
\hline Bertin & 26,9 & 2008 \\
\hline JBS & 19,4 & 2007 e 2008 \\
\hline Marfrig & 14,7 & 2008 \\
\hline Perdigão/BR Foods & 2,55 & $2007 / 2009$ \\
\hline
\end{tabular}

Fonte: BNDES, 2010

Após os aportes, o JBS adquiriu a divisão de carnes do Bertin. Essas empresas tem unidades no Mato Grosso do Sul, nos seguintes municípios: JBS/Bertin - em Campo Grande e Naviraí, Marfrig em Bataguassu e a BR Foods (Perdigão + Sadia) - Dourados.

\section{O COMÉRCIO EXTERIOR BRASILEIRO E AS EXPORTAÇÕES DE MATO GROSSO DO SUL}

Em “A Dualidade Básica da Economia Brasileira” (RANGEL, 2005, p.322), Rangel escreveu que "A economia brasileira, desde a descoberta, desenvolve-se como complemento de outras economias - dos países que, sucessivamente, ocupam a vanguarda no desenvolvimento da humanidade."

O Brasil ainda é um complemento agrário-produtor de matérias-primas dos países capitalistas avançados. Embora tenha sofisticado suas exportações, a afirmação permanece como uma característica das nossas estruturas produtivas.

As características do comércio exterior desde 2003 não são apenas resultado das políticas econômicas ou das orientações definidas pela política industrial. Antes, pelo contrário, o peso dos produtos básicos é resultado da ausência de políticas industriais e de políticas de longo prazo, que 
trabalhassem na alteração das estruturas produtivas tradicionais. As estruturas produtivas tradicionais são consideradas, neste texto, pela presença do latifúndio, da pecuária extensiva e da homogeneização do território em função das demandas do mercado externo.

As recentes políticas industriais são mecanismos de intervenção pelo Estado, que procuram alterar esse quadro. O Presidente do BNDES, Luciano Coutinho, afirmou que "[...] a especialização em produtos de tecnologia madura e disponível (commodities) torna a conquista de novos mercados fortemente dependentes da obtenção de custos inferiores aos dos concorrentes, o que restringe a agregação de valor." (COUTINHO, 2003, p.338). Esse é o ponto central da política industrial brasileira, as resistências à agregação de valor. Se há demanda e a economia depende das exportações de commodities, como alterar essa sinergia?

Commodity representa produtos básicos, em estado bruto (matérias-primas) ou com pequeno grau de industrialização, de qualidade quase uniforme, produzidos em grandes quantidades e por diferentes produtores. Estes produtos in natura, cultivados ou de extração mineral, podem ser estocados por determinado período sem perda significativa de qualidade. Possuem cotação e negociabilidade globais, utilizando bolsas de mercadorias. (MDIC, 2011). Sua principal característica é que, por deter pouca variedade, a competição com os concorrentes é definida pela redução dos custos, que pode ser no processo produtivo ou na eficiência logística. Na produção de agroprimários, a redução de custo tende a implicar em superexploração da força de trabalho, na extração da mais valia absoluta e relativa, que se materializa nos preços pagos ao produtor, na remuneração do trabalho, nas práticas de terceirização abusivas e irresponsáveis juridicamente. O capitalista do campo tem adotado práticas de tercerização, principalmente nas atividades que envolvem colheita manual e são trabalho-intensivas e com essa prática, transfere o ônus trabalhista e político da superexploração do trabalho para os recrutadores de mão-de-obra. Alguns casos têm ocorrido com mais freqüência na colheita da laranja, no interior do estado de São Paulo. Outra estratégia pode ser a re-localização, incorporação de novas áreas, formação de novas territorialidades econômicas em áreas pouco tradicionais.

A evolução das exportações brasileiras, por fator agregado demonstrou que em 1979 as exportações de básicos foram superadas pelas exportações de manufaturados, o que representou o coroamento do esforço de substituição de importações e o amadurecimento do parque industrial nacional. Os primeiros anos do século XXI apresentaram um preocupante movimento inverso se considerarmos os números relativos (a proporção que cada grupo de produtos representa nas exportações). Ocorre um crescimento da participação dos produtos básicos e uma redução dos manufaturados. (Ver Figura 1). Há um conjunto de fatores que contribui para isso: a variação cambial, a perda de competitividade do setor ou oscilação na demanda via disputa de fornecedores. O movimento de expansão das exportações de produtos básicos, e a concomitante redução nas exportações de manufaturados, chegou a ser tratado como um início de desindustrialização na economia brasileira, hipótese que tem sido criticada por Barros e Pereira (2008).

Em 2009, os principais produtos exportados pelo Brasil, por valor, foram: óleos brutos de petróleo; minério de ferro e seus concentrados; açúcar de cana em bruto; soja mesmo triturada; carne de frango congelada fresca ou refrigerada em miúdos; pasta química de madeira; café cru em grão; automóveis de passeio; farelo e resíduos da extração de óleo de soja e carne de bovino congelada, fresca ou refrigerada.

A pauta de exportações do Mato Grosso do Sul mantém estreita correspondência com o "padrão" nacional. Excluindo petróleo, café e automóveis de passeio, todos os demais produtos são os mais representativos do comércio exterior do estado.

As exportações de agroprimários e minerais seguem uma tendência crescente de aumento. Em 2005-2006 a redução das exportações ocorreu em função do embargo comercial imposto à carne bovina, devido ao problema sanitário com os focos de febre aftosa. O embargo é o fato jurídico que representa o peso da proteção dos mercados nacionais pelos países desenvolvidos. Trata-se 
de formas de proteção de setores que são subsidiados para a proteção dos mercados nacionais. Os embargos se legitimam a partir de critérios técnicos que são deliberados politicamente.

Os países superavitários podem restringir a compra de produtos brasileiros se valendo dos mecanismos reguladores - como tarifas - e da política de cotas. No caso da carne bovina, a União Européia impõe cotas para importação de cortes nobres, chamada Cota Hilton. Essa cota é uma parcela de exportação de carne bovina sem osso, de alta qualidade e valor, que a União Européia outorga anualmente a seus principais fornecedores internacionais. A cota surgiu em 1979, nas negociações multilaterais comerciais do GATT (Acordo Geral de Tarifas e Comércio) na Rodada de Tóquio, em um hotel da cadeia Hilton (dali a origem de seu nome).

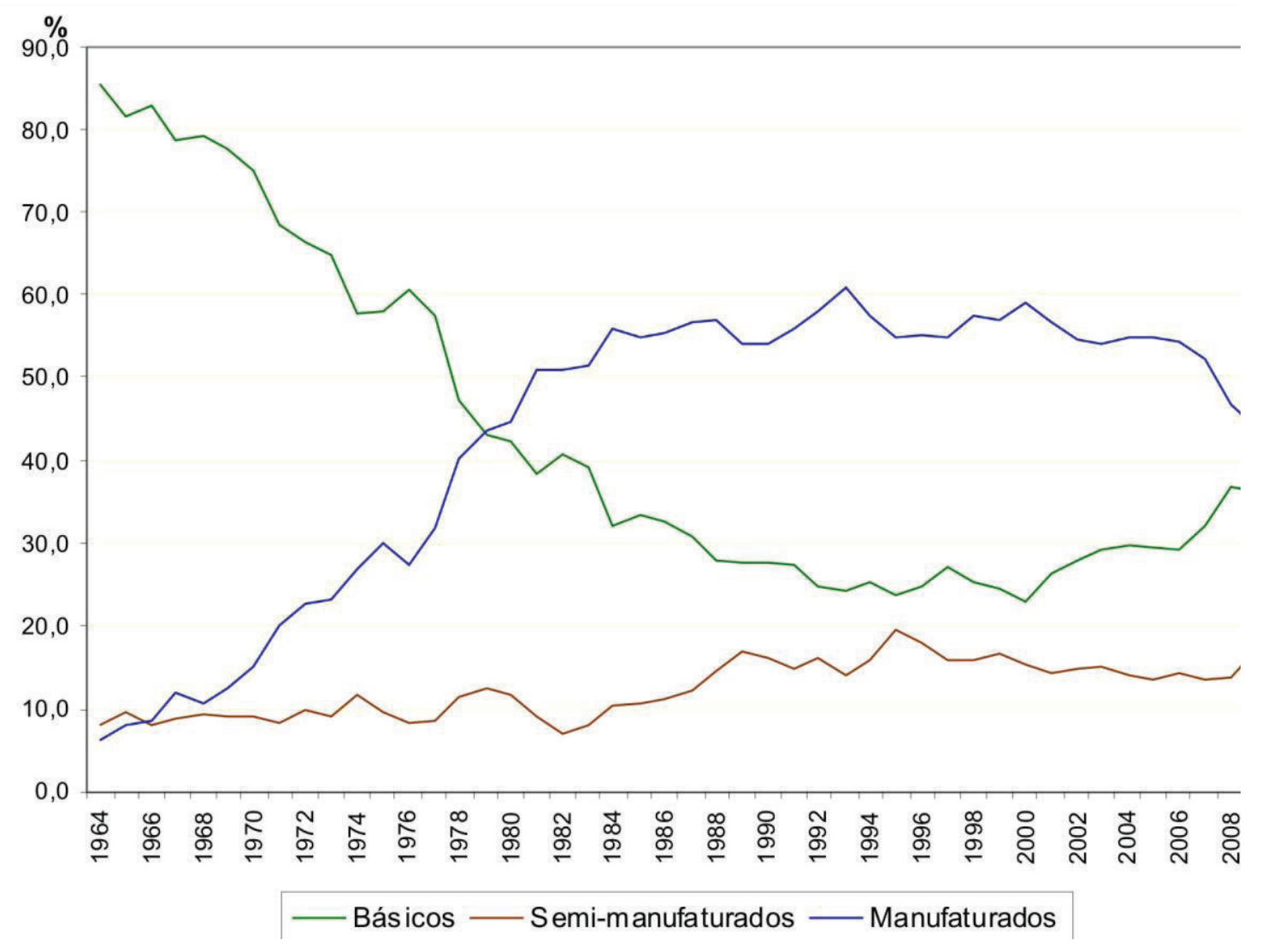

Figura 1 - Exportações brasileiras por fator agregado (1964-2009) (participação percentual sobre o total geral) Fonte: Secex/MDIC, 2010

Da mesma forma que apresentamos a evolução das exportações por fator agregado para o Brasil, faremos com os dados do Mato Grosso do Sul, a partir do ano 2000, conforme pode ser visualizado na Figura 2.

A Cota Hilton é mais uma norma que, no caso, organiza a distribuição do lucro em favor do frigorífico exportador, que no Mato Grosso do Sul representa o vencedor na disputa entre o capital da agropecuária e o monopólio industrial, conferindo ao último a maior fração da renda da terra. O agronegócio do estado não tem exclusividade do poder político pois é subordinado também. Da fazenda capitalista para o frigorífico exportador ocorre uma transferência de renda, que é constatada quando o pecuarista torna-se refém do preço da arroba determinado pelo mercado e pela concentração de compradores. Não temos estudos, mas há indícios de oligopsônio na frigorificação da carne bovina. Os lucros do setor exportador de carne bovina se realizam apenas parcialmente no estado, através do reinvestimento. Parte, que não foi possível mensurar até então, é drenada para a matriz localizada em municípios paulistas. Nenhum frigorífico exportador tem participação de 
capital privado regional.

A queda das exportações no ano de 2008 foi motivada pela crise financeira, que reduziu tanto as exportações quanto interferiu no preço das commodities. Isso confere materialidade à idéia de que no território se manifestam os vetores da globalização, a influência do centro dinâmico da economia internacional e suas tendências político-econômicas e produtivas. Como as exportações do estado estão baseadas em commodities, a arrecadação estadual - que se reflete na municipal é acionada em conexão direta com o mercado externo, quanto mais dependente for de uma base produtiva pouco diversificada.

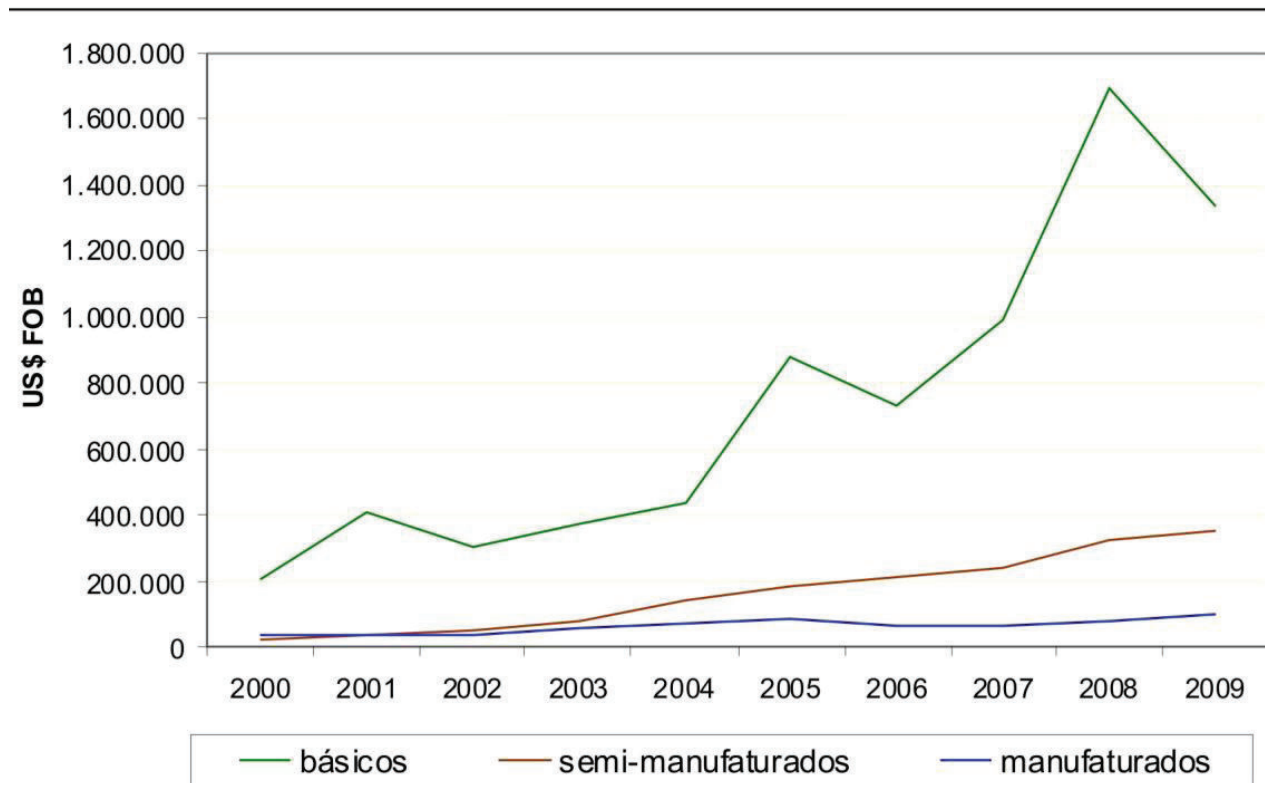

Figura 2 - Exportações de Mato Grosso do Sul por fator agregado (2000-2009) Fonte: Secex/MDIC, 2010

Em 2010, a distribuição das exportações do estado apresentou 70,71\% de bens intermediários (30,49\% para alimentos e bebidas destinados à indústria; 40,14\% de insumos industriais e $0,08 \%$ de peças e acessórios de equipamentos e transportes). Em segundo lugar, os bens de consumo, com $28,64 \%$ (com predomínio dos bens de consumo não duráveis - 28,54\%). Bens de capital representaram apenas 0,51\%. (MDIC, 2011).

A Tabela 3 apresenta as porcentagens dos principais produtos exportados no total da pauta do estado. Anualmente a soja alterna com a carne bovina como um dos produtos mais exportados, mas com a expansão do reflorestamento e da produção de celulose, a soja é seguida pela pasta química de madeira (Fibria, em Três Lagoas). Se agruparmos, 12,56\% da participação da carne bovina e $37,35 \%$ do complexo soja, a expressão do binômio soja-boi responderá por quase $50 \%$ do total exportado. Para chegar à estrutura produtiva industrial e comercial que processa essas mercadorias, selecionamos as quinse maiores empresas exportadoras do ano de 2010, em ordem decrescente de valor exportado (US\$ FOB) e a variação 2010/2009 e organizamos a Tabela 4.

As quinze maiores empresas exportadoras de 2010 responderam por $75,05 \%$ do valor total exportado pelo estado. Consideramos que esses agentes exportadores exercem o que Santos denominou como "poder de mando" (SANTOS, 1996, p.162). Ao se localizarem escolhem os espaços regionais de acordo com a capacidade que os mesmos apresentam para possibilitar o aumento da produtividade e do lucro. Como se trata, em sua maioria de produtos de baixo valor agregado, a competitividade é baseada na capacidade dos agentes em reduzirem seus custos de produção e de implementarem o melhor plano de logística. Os espaços são apropriados pelos agentes exportadores de acordo com a produtividade espacial que oferecem e um pouco mais que isso, quando conside- 
ramos a proposta de Veltz (1996). Para esse autor, que trabalha com a noção de "territórios-rede", os territórios são mais que repositórios de objetos técnicos. No Mato Grosso do Sul o território apresenta um conjunto de relações imateriais que também é apropriada, como a tradição econômica, a experiência acumulada pelos agentes econômicos e políticos, o conhecimento dos caminhos da comercialização, do crédito, as relações com os prestadores de serviços como motoristas, mecânicos, escritórios de planejamento etc.

Tabela 3 - MATO GROSSO DO SUL - Principais Produtos Exportados (em porcentagem do valor total)

\begin{tabular}{c|l|c}
\hline ORIDEM & \multicolumn{1}{|c}{ Produtos } & \% do valor total \\
\hline 1 & Carne desossada de bovino, congelada & 18,31 \\
\hline 2 & Outros grãos de soja, mesmo triturados & 17,43 \\
\hline 3 & Bagaços e outros resíduos sólidos da extração do óleo & 10,31 \\
\hline 4 & Pedaços e miudezas comestiveis de galos e galinhas congelados & 9,47 \\
\hline 5 & Açúcar de cana, em bruto & 8,66 \\
\hline 5 & Minérios de ferro não aglomerados & 5,54 \\
\hline 7 & Pasta química de madeira & 4,20 \\
\hline 8 & Carnes de galos e galinhas não cortadas em pedaços & 2,66 \\
\hline 9 & Milho em grão, exceto para semeadura & 2,37 \\
\hline 10 & Carnes desossadas de bovino frescas ou refrigeradas & 2,16 \\
\hline
\end{tabular}

Fonte: SECEX/MDIC, 2010

Esta produtividade espacial não é definida apenas na escala regional ou nacional, pois as exportações são administradas por corporações que atuam na escala global, segundo as regras da concorrência capitalista. Os espaços regionais estão, portanto, submetidos às comparações definidas segundo critérios postos pelo entrelaçamento dos níveis escalares de decisão.

Tabela 4 - Participação das quinze maiores principais empresas exportadoras no total exportado pelo estado de Mato Grosso do Sul no ano de 2010 e a variação 2010/2009

\begin{tabular}{|c|c|c|c|}
\hline ORDEM & Empresa & $\%$ do valor total & Variação \\
\hline 1 & Fibria-MS Celulose Sul Mato-grossense Ltda. & 13,50 & 76,03 \\
\hline 2 & JBS S/A & 8,91 & 218,61 \\
\hline 3 & ADM do Brasil Ltda. & 7,20 & 6,54 \\
\hline 4 & Bunge Alimentos S/A & 6,42 & 134,76 \\
\hline 5 & Seara Alimentos S/A & 6,32 & 23,82 \\
\hline 6 & Mineração Corumbaense Reunida S/A & 6,26 & 510,72 \\
\hline 7 & Cargill Agrícola S/A & 6,22 & 37,62 \\
\hline 8 & Tavares de Melo Açúcar e Álcool S/A & 4,31 & 78,20 \\
\hline 9 & Minerva S/A & 3,09 & 43,96 \\
\hline 10 & Urucum Mineração S/A & 2,60 & 18,17 \\
\hline 11 & Bertin S/A & 2,52 & $-64,27$ \\
\hline 12 & BRF Brasil Foods S/A & 2,38 & 40,84 \\
\hline 13 & Cooperativa Agropecuária Mouraoense Ltda. & 1,98 & 37,73 \\
\hline 14 & Doux Frangosul A/A Agro Avícola Industrial & 1,89 & 7,49 \\
\hline 15 & Louis Dreyfus Commodities Brasil S/A & 1,45 & 66,37 \\
\hline
\end{tabular}

Fonte: MDIC, 2011

A base exportadora do Mato Grosso do Sul revela o papel que foi destinado ao agronegócio para conter o défict que se abriu na balança comercial com as políticas neoliberais dos anos noventa. E nem se trata de um elogio ao setor, mas do reconhecimento do pacto de poder político que foi firmado no país que resulta no fortalecimento de uma classe, no Mato Grosso do Sul, bastante conservadora políticamente, com características de um acentuado patrimonialismo-rentista. 
O apego à propriedade da terra revela a ausência de investimentos regionais na verticalização das estruturas produtivas. Da lista das 500 maiores empresas do agronegócio, por receita líquida, do ranking elaborado pela Revista Globo Rural (2008), apenas 3 empresas tem sede no estado, nas seguintes posições: $111^{\circ}$ - Cooagri (Dourados), $186^{\circ}$ BMZ Couros (Campo Grande), $252^{\circ}$ Copasul. A Cooperativa Agroindustrial (Coagri) pediu falência. Resta uma empresa organizada na forma de cooperativa que comercializa algodão e a BMZ, que exporta o couro wet blue, primeiro estágio do beneficiamento. O pedido de falência da principal cooperativa do estado, a Cooagri, no segundo semestre de 2009, criou uma situação de incerteza e paralisação para os 3.500 cooperados. Direta ou indiretamente, essas transformações espraiam-se para as economias municipais, afetando a atividade comercial varejista, a cadeia de serviços formada por revendedoras de produtos agropecuários, concessionárias de veículos agrícolas, rede de abastecimento de combustível e o setor de transporte de cargas, além de reduzir a arrecadação do poder público.

\section{AS RELAÇÕES ENTRE A ECONOMIA EXPORTADORA E O TERRITÓRIO}

O atual estado do Mato Grosso do Sul, antes de 1979, compunha o sul do estado de Mato Grosso. O processo de ocupação teve três "portas de entrada", pelo Planalto (via Monções), pelo Pantanal (através da navegação pelo Rio Paraguai, pelo Porto de Corumbá) e pelo Sul. Neste processo de ocupação, a pecuária extensiva adquiriu um caráter fundamental na formação sócio-espacial (BERTHOLI, 2006). A ocupação se intensificou após a Guerra do Paraguai (1864-1870), com a ocupação da erva mate e, findo este monopólio, com a pecuária extensiva que foi formada a partir dos latifúndios, historicamente sob a posse de famílias que imprimiram sua marca também na esfera política. Bittar (2009) aprofunda em seu texto as relações de parentesco e a formação da elite política sul-matogrossense, destacando o papel dos pecuaristas na política estadual.

Na porção meridional do estado de Mato Grosso do Sul, os investimentos realizados pelos diversos programas de desenvolvimento regional, com destaque para a atuação da SUDECO, o papel do Sistena Nacional de Crédito e, mais recentemente, o "Luz Para Todos", implantaram no território uma rede técnica que passou a permitir a aproximação dos lugares, a relativização das distâncias e uma subversão da ordem hierárquica urbana. Investimentos agroindustriais não mais concentram-se apenas em cidades pólos regionais, como Dourados e Três Lagoas, mas também se fixam em municípios com menos de quarenta mil habitantes e que antes não apresentavam condições materiais atrativas para as empresas. Citando Whithead:

Os lugares e seus fixos continuam na mesma posição, mas diferentes distâncias passam a existir entre eles, tornando-os mais próximos ou mais distantes de cada empresa, instituição ou indivíduo conforme a velocidade com a qual cada um cria seus fluxos entre esses mesmos lugares, o que depende dos diferentes tipos e qualidades de sistemas de engenharia disponíveis, nas normas e da capacidade que cada um tem para deles fazer uso. (WHITHEAD, 1994, p.126-127).

O processo de ocupação, em suas "rugosidades" (SANTOS, 1986), produziu condições para o fortalecimento da pecuária como atividade econômica, o que pode ser expresso pela inserção internacional dos frigoríficos exportadores localizados em Campo Grande, Naviraí e Batayporã. Galera (2010) apontou as seguintes localizações dos frigoríficos exportadores em 2009, no estado: Frigorífico Margem, em Coxim, Parnaíba, Três Lagoas, Batayporã e Naviraí; Frigorífico Independência (Anastácio, Campo Grande e Nova Andradina); JBS, em Campo Grande, Bertin em Naviraí e Marfrig, em Bataguassu. A maioria deles se localiza em municípios da Bacia do Rio Paraná, sendo seis deles vizinhos ou próximos do estado de São Paulo, que é um importante mercado consumidor e também a via de escoamento para o acesso ao complexo portuário marítimo.

Embora com forte especialização na exportação de commodities, não consideramos que os municípios possam ser chamados como uma "família de municípios do agronegócio", expressão 
que Silva (2009) utiliza com bastante propriedade para caracterizar o processo de criação de municípios no estado de Mato Grosso. No caso de Mato Grosso do Sul, há uma heterogeneidade ainda por força da diversificação rural e da presença dos produtores familiares principalmente na porção meridional do estado, por um conservadorismo produtivo na bacia do Rio Paraguai, que a despeito de ter volume de rebanho, não apresenta nenhum frigorífico inserido na economia de exportação, portanto com produção em escala.

A mineração de ferro e manganês, em Corumbá, utiliza a navegação pelo Rio Paraguai para suas exportações no mercado platino, Argentina e Paraguai. As exportadoras de soja formam uma rede concentrada na porção meridional, com Dourados, Maracaju e Caarapó como centros urbanos de suporte e Três Lagoas, através da Ferronorte, possibilita um volume de exportação pela via férrea, em direção ao porto de Santos. Os municípios de Sonora, Pedro Gomes, Chapadão do Sul e São Gabriel do Oeste, na porção setentrional, também são importantes centros de suporte para as tradings de grãos.

O processo de desenvolvimento econômico, baseado na aliança entre o capital industrial e a fazenda capitalista e as orientações da Política de Desenvolvimento Produtivo tem repercutido no Mato Grosso do Sul no sentido de fortalecer a cadeia do agronegócio sob a hegemonia das empresas transnacionais de capital estrangeiro.

O poder de mando da economia exportadora é exercido pelas unidades das empresas transnacionais e por uma ex-estatal, a Vale, que por imposição geológica, concentra suas operações na Morraria do Urucum. A comercialização dos grãos é monopolizada pelas tradings do ABCD (ADM, Bunge, Cargill e Dreiffus). Suas unidades estão instaladas predominantemente no espigão divisor das Bacias do Rio Paraguai e Rio Paraná, por onde passa o principal eixo de circulação, que é a BR 163. Na porção Nordeste do estado, um sub-eixo da exportação de grãos ocorre em função do traçado da Estrada de Ferro Ferronorte, com Três Lagoas funcionando como importante centro urbano de concentração de cargas.

A recente expansão das usinas de açúcar e álcool começou no estado com a implantação de usinas por grupos de capital privado nacional e posteriormente, o processo de internacionalização no campo foi materializado por aquisições e fusões sob o domínio do capital estrangeiro. Trabalho de Backes apontou que "60\% do capital investido no Mato Grosso do Sul (dados até 2008), pelo setor sucroalcooleiro possui, direta ou indiretamente, participação do capital estrangeiro" (BACKES, 2009, 112). A internacionalização está presente no setor de commodities no estado e esse processo de implantação das usinas ocorre através da prática de arrendamento de terras, configurando o processo de "monopolização do território pelo capital" (OLIVEIRA, 1996). A agroindústria da cana, mais que açúcar e álcool, faz parte de um setor estratégico geopoliticamente, que é a geração de energia - setor sucro-álcool-energético - e por isso atrai ainda mais investimentos. O capital regional não tem conseguido se contrapor ou competir com os investimentos das coorporações de capital privado nacional e investimentos estrangeiros. Por isso, as usinas montadas originalmente com capital regional são vendidas para os grupos estrangeiros, que participam do mercado de ações, tem acesso a crédito subsidiado captado no exterior ou no BNDES.

A figura 1 apresenta a localização de onze unidades exportadoras: Fibria, duas unidades do frigorífico JBS, Frigorífico Minerva, duas unidades da Seara Alimentos, Mineração Corumbaense, Urucum Mineração, Bungue e Cargill Agrícola. Estas unidades exportaram acima de US\$ 50 milhões em 2010, segundo dados do MDIC (2011).A maior exportadora foi a Fibria, com US\$ 399.891.940, representando um aumento percentual em relação ao ano anterior de 76,03\%. O papel de cidade pólo, que foi definida pelos planos de desenvolvimento industrial nos anos setenta, mantém correspondência com a expressão ocupada por Três Lagoas(com unidade da Cargill e da Fibria), de Corumbá (com a atuação da mineração) e Dourados (com a Seara e a Bunge). 


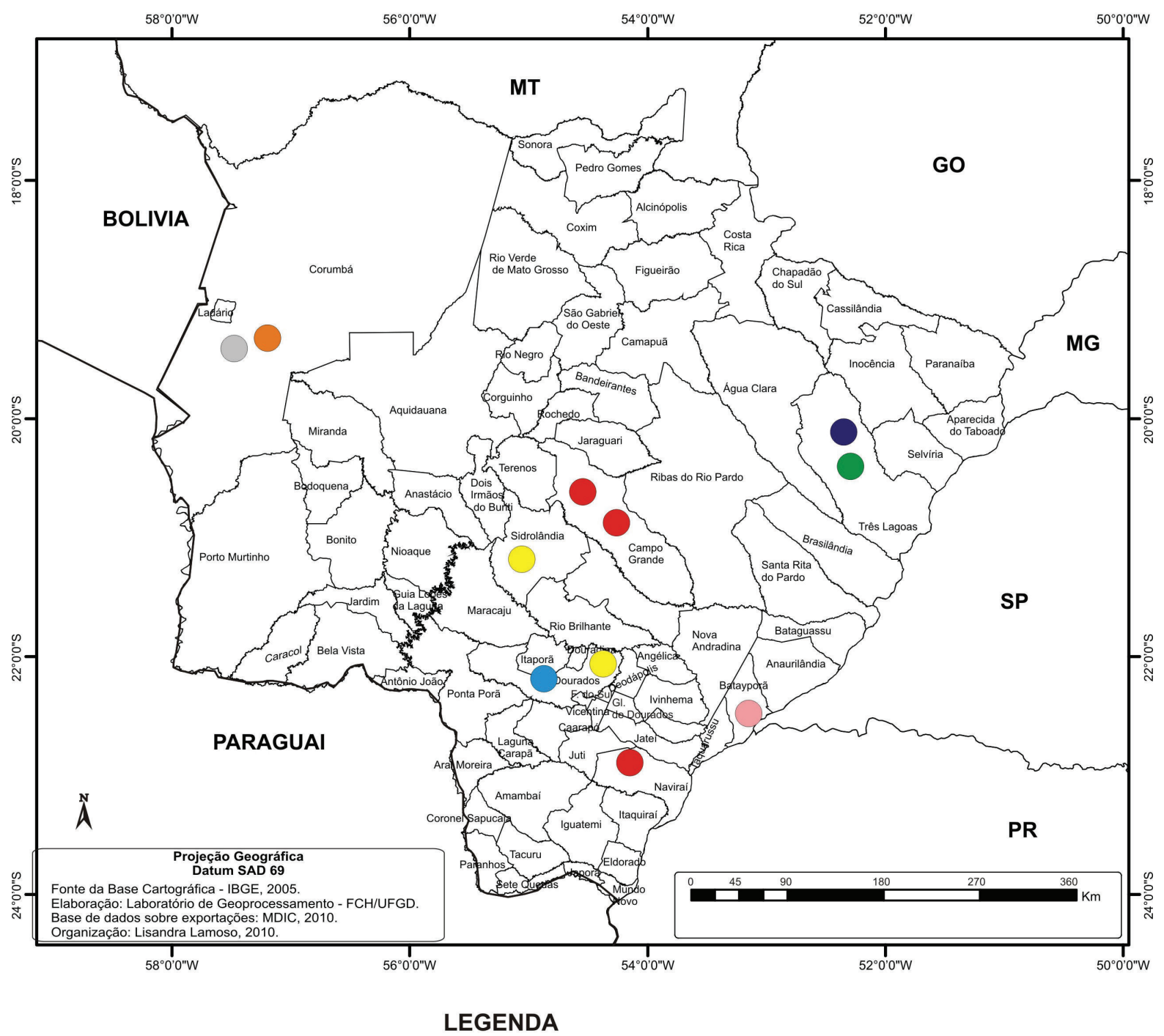

\section{Unidades das empresas exportadoras}

FIBRIA - MS Celulose Sul-mato-grossense Ltda.

Frigorífico JBS S/A

Frigorífico Minerva S/A

Seara Alimentos S/A

Mineração Corumbaense S/A (Vale)

Urucum Mineração S/A (Vale)

Bunge Alimentos S/A

Cargill Agrícola S/A

Figura 3 - Localização das unidades que exportaram acima de US\$ 50 milhões em 2010 
Para a economia de exportação, quatro pontos da organização em rede estão presentes no mapa do Mato Grosso do Sul: mineração de metálicos (Corumbá), celulose (Três Lagoas), agroindústria (Sidrolândia e Dourados), carne bovina (Campo Grande, Naviraí e Bataiporã). Considerando que os volumes exportados pela unidade da Cargill de Três Lagoas são resultado da produção do entorno, Chapadão do Sul, Aparecida do Taboado, Cassilândia.

\section{CONSIDERAÇÕES FINAIS}

As dinâmicas produtivas da economia de exportação em Mato Grosso do Sul possuem dois vetores de determinação a) a estrutura produtiva da economia brasileira e b) a influência do centro dinâmico através das demandas do mercado internacional.Como parte da estrutura produtiva nacional este sub-espaço continua desempenhando o papel de extensão do mercado paulista e, no caso dos grãos, também do mercado paranense, através da atuação das cooperativas.

No rol de mercadorias exportadas predominam o complexo soja (grãos, farelo, óleo) e a pecuária. São os frigoríficos, num quase monopólio do Grupo JBS, que inserem no comércio internacional cidades como Naviraí e Batayporã. As transnacionais predominam na exportação de grãos e na cadeia sucro-álcool-energética. As exportações de carne bovina são lideradas pelo JBS (transnacional de capital privado nacional com aportes do BNDES). O minério de ferro e manganês, monopolizado pela Vale, que desde 2009 comprou a concorrência representada pela empresa Rio Tinto. (A Vale adquiriu da Rio Tinto, a Mineração Corumbaense Reunida).

As empresas que estão no rol das maiores exportadoras tem sua sede em São Paulo. Como território de influência do mercado internacional há o peso da atuação das tradings de grãos, que se concentram no espigão divisor entre as Bacias dos Rios Paraguai e Paraná, por onde passa o principal eixo de circulação do estado, a BR 163. Uma subconcentração de tradings ocorre na porção nordeste do estado, no eixo da Estrada de Ferro Ferronorte, onde o município de Três Lagoas representa um ponto de suporte.

A intervenção do Estado na economia de exportação ocorre através da política industrial implantada nos últimos oito anos, que incentiva o comércio exterior, a utilização das vantagens comparativas tradicionais e a internacionalização dos grupos de capital privado nacional. Isto tem fortalecido sobremaneira o setor de carne bovina que é representado pelo Grupo JBS, que tem adquirido plantas industriais de concorrentes, aumentando sua escala de exportação e de oligopolização.

A rede urbana fornece uma base logística, com seus objetos sociotécnicos que propiciam a intensificação dos fluxos materiais e imateriais, para circulação de mercadorias e informações. Alguns núcleos, como Três Lagoas, Sidrolândia e Dourados parecem ter oferecido condições propícias à introdução, difusão e absorção das filiais das empresas lá instaladas através do equipamento urbano, da presença de profissionais especializados e de uma rede de serviços. A capital, Campo Grande, centro da diversificação industrial do estado, participa da economia de exportação apenas através da carne bovina, com pequena expressão para a soja.

Além do complexo soja e da carne bovina, o setor mineral oscila diretamente em função da demanda interna e se concentra em Corumbá, cidade que possui uma dinâmica econômica que não depende exclusivamente do comércio internacional de minérios, pois mantém um dinâmico comércio formal e informal com a cidade gêmea de Puerto Suarez, na Bolívia, além de outras atividades industriais e de serviço.

As exportações emergem como resultado do processo de integração territorial do mercado doméstico, com a expansão da frigorificação de carnes para próximo das áreas de engorda e a participação do Cerrado na produção de commodities para a exportação, principalmente a partir dos anos setenta.

Como ponto em comum nessa dinâmica produtiva voltada para a economia de exportação está o fato da ausência de capitais privados de origem regional, o que leva a indagar sobre as razões que levaram os capitalistas sul-matogrossenses a não encarnarem o espírito empreendedor marshalliano 
e se utilizarem de créditos subsidiados e incentivos fiscais para montarem empreendimentos geuninamente regionais. As empresas regionais não "sobreviveram" para alcançar a escala exigida pelo comércio internacional. O Grupo JBS adquiriu frigoríficos que já estavam em funcionamento, as tradings assim como as cooperativas tem adquirido ou arrendado as instalações de processamento de grãos e as usinas de capital estrangeiro tem comprado unidades originalmente montadas com capital regional, num claro e veloz processo de internacionalização.

A rede do comércio exterior se materializa no Mato Grosso do Sul através das dinâmicas produtivas que se valem das vantagens comparativas e competitivas, da inércia espacial, de heranças do próprio processo de ocupação (dado pela pecuária e pela produção de grãos), da interferência dos vetores externos (formados pelo par: política econômica nacional/demanda internacional). Os vetores externos definem as ligações em rede de frações do território com outros pontos, com a mediação do poder de mando das corporações. Essa composição resulta num processo de transferência de renda desta fração do território para fora, tanto da renda da fazenda capitalista de base pecuária, da produção familiar de integrados à agroindústria, dos produtores de grãos, dos trabalhadores urbanos e rurais, com destaque para a colheita manual da cana de açúcar, ainda vigente.

\section{AGRADECIMENTOS}

Pesquisa com auxílio financeiro do CNPq e da Fundação de Apoio ao Desenvolvimento do Ensino, Ciência e Tecnologia do Estado de Mato Grosso do Sul (Fundect).

\section{REFERÊNCIA BIBLIOGRÁFICA}

ALMEIDA, Mansueto. Desafios da real política industrial brasileira do século XXI. Textos para Discussão IPEA - n, 1452. Brasília, 2009. Disponível em <http://www.ipea.gov.br/sites/000/2/publicacoes/tds/td_1452. pdf $>$. Acesso em 15 jan. 2010.

BACKES, Thaine. O capital agroindustrial canavieiro no Mato Grosso do Sul e a internacionalização da produção. 2009. Dissertação (Mestrado em Geografia). Faculdade de Ciências Humanas, Universidade Federal da Grande Dourados. Disponível em < http://www.ufgd.edu.br/fch/mestrado-geografia/dissertacoes/ thaine-regina-backes> Acesso em: 5 mai. 2010.

BARROS, Octavio de; PEREIRA, Robson Rodrigues. Desmistificando a tese da desindustrialização: reestruturação da indústria brasileira em uma época de transformações globais. In: BARROS Octavio de; GIAMBIAGI, Fabio (Org.) Brasil globalizado. Rio de Janeiro : Campus, 2008. p.299-330.

BERTHOLI, Anderson. O lugar da pecuária na formação sócio-espacial sul-matogrossense. 2006. Dissertação (Mestrado em Geografia). Centro de Filosofia e Ciências Humanas. Universidade Federal de Santa Catarina, 2006.

BITTAR, Marisa. Mato Grosso do Sul - a construção de um estado: regionalismo e divisionismo no sul de Mato Grosso. Vol. 1. Campo Grande : Editora da UFMS, 2009.

COUTINHO, Luciano; SARTI, Fernando. A política industrial e a retomada do desenvolvimento. In: LAPLANE, Mario et. al. Internacionalização e desenvolvimento da indústria no Brasil. São Paulo : Editora da Unesp/Instituto de Economia da Unicamp, 2003. p.333-347.

GALERA, Maurício Martorelli. A inserção dos frigoríficos exportadores de Mato Grosso do Sul no mercado global. 2010. 109f. Dissertação (Mestrado em Geografia). Faculdade de Ciências Humanas, Universidade Federal da Grande Dourados, Dourados, 2010.

GOLDENSTEIN, Lea; SEABRA, Manoel. Divisão regional do trabalho e nova regionalização. In Secretaria de Estado de Educação de São Paulo. Fundamentos para o ensino de geografia - seleção de textos. São Paulo, CENP, 1989, p.45-69

OLIVEIRA, Ariovaldo Umbelino de. Agricultura camponesa no Brasil. 2ed. São Paulo : Contexto, 1996. MAILLAT, Denis. Globalização, meio inovador e sistemas territoriais de produção. Interações, Campo Grande, v. 4, n.3, p.9-16, mar. 2002. 
MINISTÉRIO DO DESENVOLVIMENTO, INDÚSTRIA E COMÉRCIO. Estatísticas de comércio exterior - DEPLA. Disponível em: < http://www.mdic.gov.br > Acesso em: 19 de abril de 2011. 2009.

MINISTÉRIO DO DESENVOLVIMENTO, INDÚSTRIA E COMÉRCIO. Política de Desenvolvimento Produtivo. Disponível em <http://www.mdic.gov.br/pdp/ > Acesso em: 24 de abr. 2010.

RANGEL, Ignácio. Ciclo, tecnologia e crescimento. In: BENJAMIM, Cesar (org). Obras reunidas. v.2, São Paulo: Contraponto, 2005. p. 255-408.

RANGEL, Ignácio. Dualidade básica da economia brasileira. 2ed. [s.1.] : Instituto Ignácio Rangel/Bienal, 1999.

REVISTA GLOBO RURAL. Anuário do Agronegócio 2008. n.4 .São Paulo : Editora Abril, out. 2008.

SADER, Emir. Brasil, de Getúlio a Lula. In: SADER, Emir e GARCIA, Marco Aurélio (orgs). Brasil, entre o passado e o futuro. São Paulo : Editora da Fundação Perseu Abramo/Boitempo, 2010. pp. 11-29.

SANTOS, Milton. A natureza do espaço. São Paulo: Hucitec, 1996.

SANTOS, Milton. Por uma Geografia Nova. São Paulo : Hucitec, 1986.

SANTOS, Milton. Técnica, espaço, tempo: Globalização e Meio Técnico-Científico Informacional. São Paulo : Hucitec, 1994.

SILVA, Silvia Cristina da. A criação de municípios no front e a formação da elite do agronegócio: faces do uso do território brasileiro. Geosul, Florianópolis, v. 24, n. 48, p.85-101, jul./dez., 2009.

WHITHEAD, Alfreed North. O conceito de Natureza. São Paulo : Martins Fontes, 1994.

VELTZ, Pierre. Mundialización, ciudades y territórios. Barcelona : Editorial Ariel, 1996.

Trabalho enviado em janeiro de 2011

Trabalho aceito em abril de 2011 